\title{
Solitary Infratentorial Tuberculoma Mimicking Tumour in a Paediatric Patient: A case report
}

\author{
Intan Bazilah Abu Bakar ${ }^{1}$, Zaharul Azran Zahari ${ }^{2}$, Radhiana Hassan ${ }^{1}$ \\ ${ }^{1}$ Department of Radiology, Kulliyyah of Medicine, International Islamic University \\ of Malaysia \\ ${ }^{2}$ Department of Neurosurgery, Hospital Tengku Ampuan Afzan, Kuantan \\ Presenter: Intan Bazilah Abu Bakar
}

Central nervous system (CNS) tuberculosis is a rare form of extrapulmonary tuberculosis, which account for about $5 \%$ of cases. It is the most hazardous type of systemic Tuberculosis (TB) due to its high mortality rate and possible of causing serious neurological complication. In the CNS Tuberculosis, meningitis and tuberculoma are the common radiological findings, whilst rarely an abscess. Tuberculoma is a granulomatous inflammatory process that may imitate a neoplasm, both clinically and radiologically. We herein report the case of a 2-year old girl who presented with unusual clinical and imaging studies of tuberculoma, mimicking an intracranial tumour. This case highlights the challenges in making the diagnosis, until a proper treatment is made. 